Article

\title{
On the Superplastic Deformation in Vanadium-Alloyed High-Nitrogen Steel
}

\author{
Elena Astafurova ${ }^{\circledR}$, Valentina Moskvina, Marina Panchenko, Galina Maier, Eugene Melnikov, \\ Kseniya Reunova, Nina Galchenko and Sergey Astafurov * (D) \\ Institute of Strength Physics and Materials Science SB RAS, 2/4 Akademicheskii ave., Tomsk 634055, Russia; \\ elena.g.astafurova@gmail.com (E.A.); valya_moskvina@mail.ru (V.M.); panchenko.marina4@gmail.com (M.P.); \\ galinazg@yandex.ru (G.M.); melnickow-jenya@yandex.ru (E.M.); reunova.ksenya@mail.ru (K.R.); \\ galchenko_nikon04@mail.ru (N.G.) \\ * Correspondence: svastafurov@gmail.com; Tel.: +7-999-495-0978
}

Received: 7 November 2019; Accepted: 20 December 2019; Published: 23 December 2019

\begin{abstract}
The experimental evidence for the realization of a superplastic behavior with $900 \%$ elongation in V-alloyed high-nitrogen austenitic Fe-19Cr-22Mn-1.5V-0.3C-0.6N steel was proposed. Using thermomechanical processing, a misoriented grain/subgrain austenitic microstructure with a high density of deformation-assisted defects and precipitates was developed in the steel. During high-temperature tensile deformation in a temperature interval from 850 to $1000{ }^{\circ} \mathrm{C}$ and strain-rate range from $4 \times 10^{-4} \mathrm{~s}^{-1}$ to $6 \times 10^{-3} \mathrm{~s}^{-1}$, this microstructure demonstrated the characteristics of superplastic flow: elongation in the interval $400-900 \%$, strain-rate sensitivity exponent $\mathrm{m}=0.40-0.49$, grain boundary sliding mechanism. The maximum elongation to failure $(900 \%)$ was reached at deformation temperature $950^{\circ} \mathrm{C}$ and strain rate $4 \times 10^{-4} \mathrm{~s}^{-1}$.
\end{abstract}

Keywords: superplasticity; vanadium-alloyed high-nitrogen steel; austenite; precipitate hardening

\section{Introduction}

Superplasticity (SP) is an ability of a material to undergo significant (more than $300-400 \%$ ) tensile plastic elongation prior to failure [1,2]. Fine-grained structure (typically less than 10-15 $\mu \mathrm{m}$ ), relatively low strain rates (about $10^{-2}-10^{-4} \mathrm{~s}^{-1}$ ), and elevated deformation temperatures (commonly above half of a melting temperature) are the principal well-established requirements for the superplastic flow of polycrystalline metals [1-3]. Under these conditions, a diffusion creep and an intragranular slip promote grain-boundary sliding, which is the dominating mechanism of SP [1,2,4]. Superplastic behavior has been observed and comprehensively studied for $\mathrm{Ti}, \mathrm{Al}, \mathrm{Zn}, \mathrm{Ni}$, and $\mathrm{Mg}$ alloys and intermetallics [1,2]. Concerning the iron-based alloys, the majority of the papers are directed to the study of superplastic behavior in duplex steels, medium carbon steels, high carbon steels, and new medium-Mn steels [5-21]. These steels demonstrate a perspective of Fe-based materials for practical superplastic forming because of their superior superplastic-assisted elongation-to-failure higher than $3000 \%$ [21] and temperature limit of superplastic flow as low as $500{ }^{\circ} \mathrm{C}$ [12].

The development of high-nitrogen steels (HNS) in the middle of the 20th century showed the high efficiency of nitrogen use as an alloying element, solving the main problem of austenitic stainless steels-their low yield strength $[22,23]$. Solid solution hardening of steels by nitrogen has also allowed to reduce nickel content or fully exclude it because both elements are strong austenite stabilizers. Therefore, nitrogen-alloying has made the cost of Fe-based alloys more attractive. Austenitic HNSs have high corrosion resistance and high strength characteristics without significant loss in ductility and toughness [22,23]. In addition, alloying of high-nitrogen steels with vanadium can significantly increase their strength and ductility due to the formation of a fine-grained structure and 
precipitation hardening [24-27]. Despite the visible advantages of the high-nitrogen austenitic steels as a construction material, there is limited data related to the possibility of realization of superplastic flow in them. Padmanabhan [1] mentioned a result of N. Narkevich, who reported $239 \%$ elongation in Fe-20Cr-20Mn-4.7V-1.14N (mass.\%) steel tested at temperature $950{ }^{\circ} \mathrm{C}$ and strain-rate $4.6 \times 10^{-4} \mathrm{~s}^{-1}$. Such relatively high elongation was obtained for the steel after a solid-solution treatment followed by $50 \%$ cold-rolling and age-hardening at $700{ }^{\circ} \mathrm{C}$ for $1 \mathrm{~h}$. The microstructure of the steel during high-temperature tests, probably, was not strictly single-phase austenitic but also contained Cr-based and V-based nitrides. This result lied in line with those for single-phase austenitic stainless steels, in which the superplastic-assisted elongation does not exceed 280\% [1,28]. Mineura [29] reported much higher elongation (527\%) for Fe-20Cr-10Ni-0.7N (mass.\%) steel at temperature $800{ }^{\circ} \mathrm{C}$ and strain rate $8 \times 10^{-4} \mathrm{~s}^{-1}$. They used two-step cold rolling with intermediate anneal at $1000^{\circ} \mathrm{C}$ for obtaining fine-grained austenitic structure stabilized by fine chromium nitrides. Vanadium-alloying promotes a homogeneous (continuous) reaction of precipitate hardening in austenitic CrMn steels [24], and this fact could provide higher stability of the fine-grained structure during high-temperature tests as compared to chromium nitrides. Therefore, there is a potential for improvement of the values for the superplastic elongation obtained by Mineura [29].

This paper aimed to find out the superplastic characteristics in high-nitrogen V-alloyed austenitic steel Fe-19Cr-22Mn-1.5V-0.3C-0.6N (mass.\%).

\section{Materials and Methods}

An austenitic V-alloyed high-nitrogen steel Fe-19Cr-22Mn-1.5V-0.3C-0.6N (V-HNS, mass.\%) was chosen as an object of investigation. The initial cast ingot of the V-HNS was homogenized and water-quenched after a one-hour anneal at the temperature $1200^{\circ} \mathrm{C}$. After solid-solution treatment, steel plates were subjected to multistep thermal-mechanical processing that consisted of multiple room-temperature rolling to the total $80 \%$ reduction with two intermediate anneals (at $1050{ }^{\circ} \mathrm{C}$ for $1 \mathrm{~h}$ each), which were done at 50 and $66 \%$ reduction. Following the multistep thermal-mechanical processing, the $0.5 \mathrm{~mm}$ thick surface layers were removed from the bars to get rid of the effects of alloying elements depletion.

Electro-discharge machining was used to cut regular dumbbell-shaped flat tensile specimens with the tensile axis parallel to the cold-rolling direction. Mechanical grinding and a final electrochemical polish ( $50 \mathrm{~g} \mathrm{CrO}_{3}$ in $200 \mathrm{~g} \mathrm{H}_{3} \mathrm{PO}_{4}$ ) were employed to remove the entire processing-affected surface layer. The final nominal dimensions of tensile specimens were $9 \mathrm{~mm} \times 2.7 \mathrm{~mm} \times 1.5 \mathrm{~mm}$ in the gauge section.

The tensile tests were carried out in the air and at an initial strain rate in the range of $4.2 \times 10^{-4}-8.4$ $\times 10^{-3} \mathrm{~s}^{-1}$ using an electromechanical machine equipped with a high-temperature chamber (LFM-125 from Walter+Bai AG, Löhningen, Switzerland). Before starting the tensile tests, each specimen was first heated to the deformation temperature and held at deformation temperature for $5 \mathrm{~min}$. Some specimens were tensile tested in vacuum to avoid oxidation of the surfaces and to provide a microstructural characterization of deformation relief on the lateral surfaces using a PV-3012-type machine (NIIKIMP, Moscow, Russia) with the high-temperature vacuum chamber. For these specimens, electrochemical polishing was carried out accurately for producing ideal smooth (mirror-like) surface for the study of specimen surface relief after high-temperature deformation.

For microstructural analysis, a Philips CM12 (Koninklijke Philips N.V., Amsterdam, the Netherlands) transmission electron microscope (TEM) operated at an accelerating voltage of $120 \mathrm{kV}$ was employed. A scanning electron microscope (SEM) Quanta 200 3D (FEI, Hillsboro, OR, USA) equipped with an electron backscattered diffraction (EBSD) unit was used for characterization of deformation relief and grain structure of the specimens. The visualization of EBSD data was performed with the TSL OIM Analysis 6.2 (EDAX, Draper, UT, USA) software; cleaning of the EBSD-maps was used-points with a confidence index less than 0.3 were excluded from the maps. The X-ray diffraction (XRD) phase analysis was done using DRON 7 (Bourevestnik, St.-Petersburg, Russia) diffractometer with $\mathrm{Co}-\mathrm{K} \alpha$ radiations. 


\section{Results and Discussion}

Figure 1 shows a microstructure of V-HNS after solid-solution treatment and after two thermal-mechanical treatments of a cast material: cold rolling with $50 \%$ reduction and analogous cold rolling with $1 \mathrm{~h}$-anneal at $1050{ }^{\circ} \mathrm{C}$. The solution-treated structure consisted of austenitic grains of almost equiaxial shape with mainly high-angle boundaries. The average grain size was $94 \mu \mathrm{m}$. Steel microstructure also contained large particles of vanadium-based nitrides/carbonitrides, which were homogeneously distributed both in grain bodies and along grain boundaries. These coarse particles are peculiar for V-HNSs, and they do not dissolve during solid-solution treatment [25-27]. The details on the elemental composition of these V-based nitrides are described previously in [27]. The most characteristic particle sizes lied in the interval 300-400 nm; their volume fraction was $1.5 \%$. Cold rolling was not accompanied by grain refinement but provided an accumulation of deformation-assisted defects of a crystal lattice and breaking up the coarse V-based precipitates (Figure 1d). During post-deformation anneal at the temperature $1050{ }^{\circ} \mathrm{C}$, deformation microstructure recrystallized into a fine-grained austenitic structure with a high volume fraction of high-angle boundaries (Figure 1e,f). The mean grain size corresponded to the image in Figure 1e was $3 \mu \mathrm{m}$.
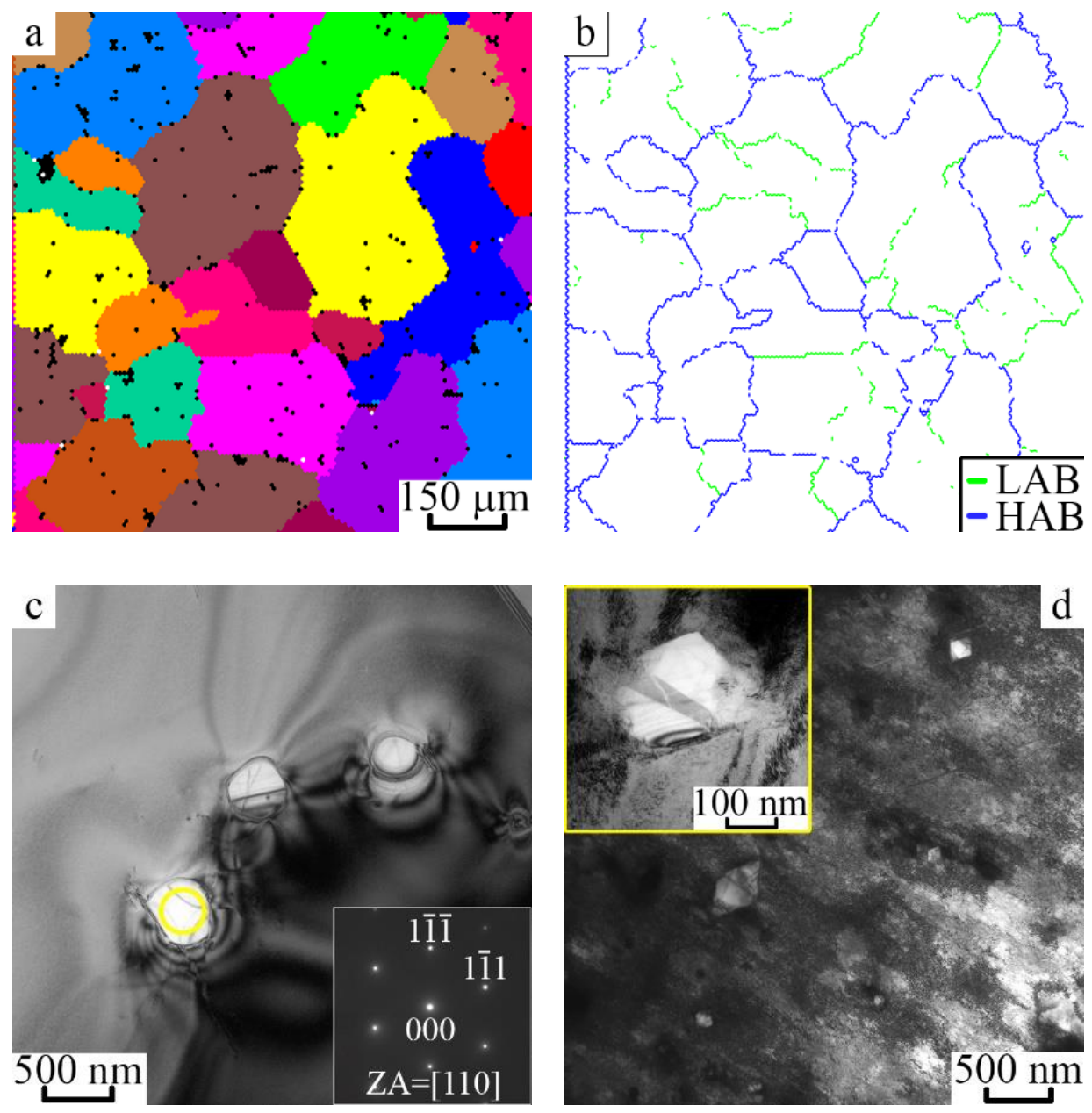

Figure 1. Cont. 

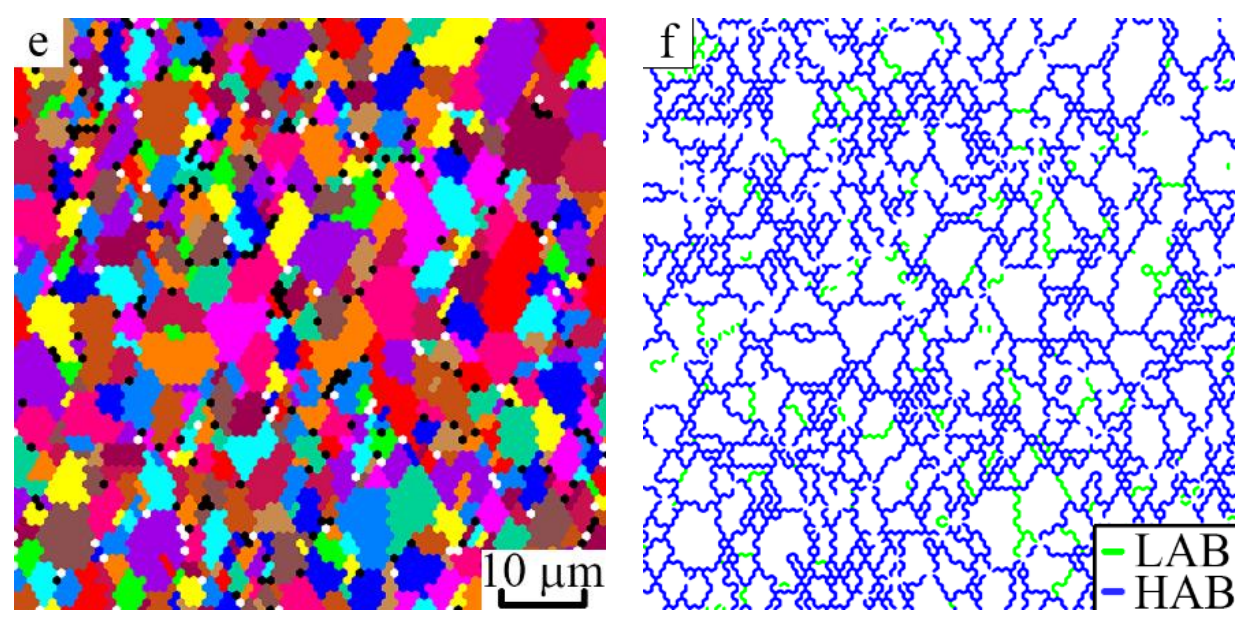

Figure 1. EBSD (electron backscattered diffraction) color-coded grain maps (a,e) and grain boundary maps (b,f), TEM bright-field images (c,d) of V-HNS (high-nitrogen steel) structure after solid-solution treatment (a-c), cold rolling with 50\% reduction (d) and cold rolling with anneal at $1050{ }^{\circ} \mathrm{C}(\mathbf{e}, \mathbf{f})$. EBSD maps in $(\mathbf{a}, \mathbf{d})$ corresponded to austenitic phase and were constructed with $C I>0.3$. Step sizes were $8 \mu \mathrm{m}(\mathbf{a}, \mathbf{b})$ and $1 \mu \mathrm{m}(\mathbf{e}, \mathbf{f})$. Selected area diffraction pattern in $(\mathbf{c})$ corresponded to the $(\mathrm{V}, \mathrm{Cr})(\mathrm{N}, \mathrm{C})$ particle (inset in c) and was obtained from the area $0.07 \mu^{2}$ (marked in yellow circle). LAB-low-angle boundaries, HAB—high-angle boundaries.

The characteristic TEM images of the steel microstructure after multistep thermomechanical processing are shown in Figure 2. A deformed austenitic structure and numerous precipitates were visible in TEM images. A complex contrast was peculiar for the matrix (austenitic) phase; it included a high density of the dislocations, which could hardly be estimated directly using TEM images (Figure 2a). Azimuthal diffusions of austenitic reflections in selected area electron diffraction (SAED) patterns were high, and they denoted the deformation-assisted continuous low-angle misorientations and high internal microstresses in the crystal lattice of austenitic grains (Figure 2b). Ferrite grains were rarely observed in TEM images. Typical SAED patterns contain reflections for austenite and nitrides. Austenitic reflections with low intensity were seen in X-ray diffraction patterns for the steel specimens after multistep thermal-mechanical treatment (Figure 2d). No X-ray lines with interplanar distances corresponded to ferrite were seen in diffraction patterns in Figure $2 \mathrm{~d}$. Therefore, its volume fraction did not exceed $5 \%$, and steel possessed a mainly austenitic structure with vanadium and chromium nitrides.

Several cycles of heating and plastic deformation promoted the rather homogeneous distribution of precipitates in the steel structure (Figure 2a). According to the TEM phase analysis, most of them were $\mathrm{Cr}_{2} \mathrm{~N}$-based phase, but coarse $\mathrm{VN}$-based particles were also present. Coarse particles marked by arrows in Figure 2a corresponded mainly to the VN-based phase inherited from the initial microstructure (after solid-solution hardening). They were elastically deformed and did not contain any dislocations. Rather small $\mathrm{Cr}_{2} \mathrm{~N}$-based particles of tens to a hundred nanometers in size gave the diffused reflections in SAED patterns (Figure 2b). The mean particle size was $214 \pm 180 \mathrm{~nm}$, with a total volume fraction of $2.7 \%$ (Figure 1a). Consequently, the multistep thermal-mechanical treatment promoted nucleation of high volume fraction of chromium-based nitrides additionally to the initial VN-based phase. 

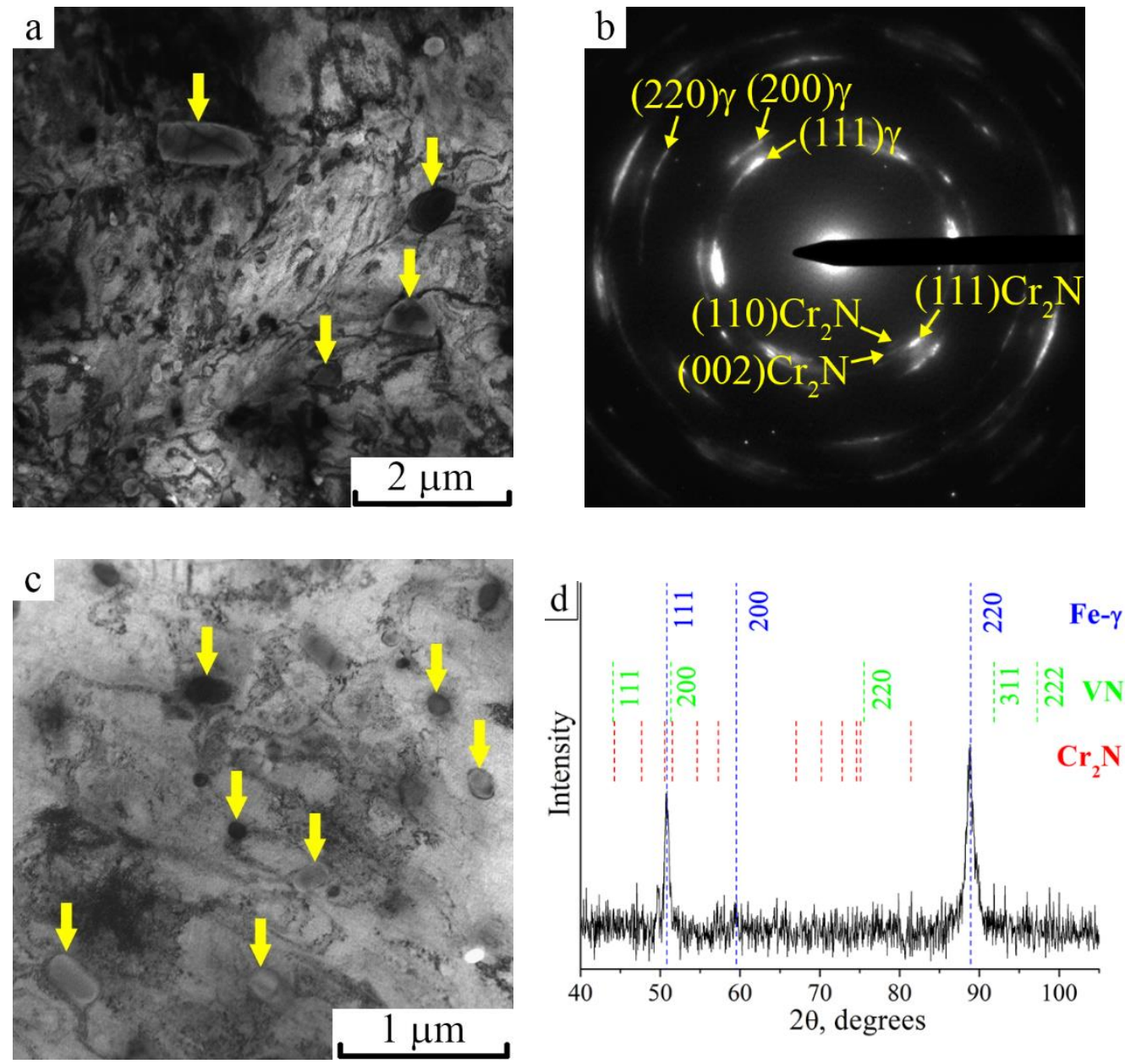

Figure 2. Representative TEM images (a-c) and X-ray diffraction pattern (d) of the microstructure in steel specimens processed via multistep thermal-mechanical treatment: $(\mathbf{a}, \mathbf{c})$ - bright-field images. Arrows in (a) and (c) show coarse vanadium nitrides and smaller chromium nitrides in the austenitic structure; $b-$ SAED (selected area electron diffraction) pattern corresponded to the image (a) and obtained from the area $0.3 \mu \mathrm{m}^{2}$.

Figure 3 shows a comparison of room temperature engineering stress vs. engineering strain diagrams for V-HNS in two different states: after 1-hour solid-solution treatment and after multistep thermal-mechanical treatment. The formation of a heterophase structure with deformation-assisted defects led to an increase in the value of $0.2 \%$ proof stress $\left(\sigma_{0.2}\right.$, yield strength) from 500 to $1270 \mathrm{MPa}$ and decreased the elongation to failure from $24 \%$ to $2 \%$. Thus, after multistep thermal-mechanical treatment, V-HNS was characterized by high strength and low ductility in room temperature tensile tests. 


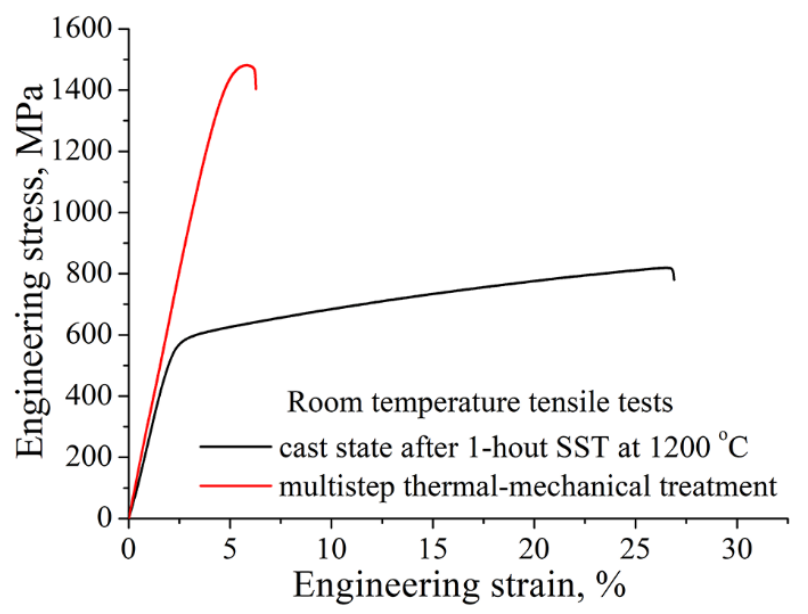

Figure 3. Engineering stress vs. engineering strain diagrams for V-HNS after solid-solution treatment and multistep thermal-mechanical treatment.

The representative high-temperature engineering stress vs. engineering strain diagrams and the photographs of the specimens after deformation to failure and some mechanical characteristics of the specimens processed via thermal-mechanical treatment are shown in Figure 4. In the given strain-rate range $4.2 \times 10^{-4}-8.4 \times 10^{-3} \mathrm{~s}^{-1}$ and temperature interval $800-1000{ }^{\circ} \mathrm{C}$, the elongation to failure of the specimens was high (hundreds percent) and flow stresses were low (down to $10 \mathrm{MPa}$ ) (Figure 4a,d, Table 1). The form of stress-strain diagrams was peculiar for superplastic flow (Figure 4a). Generally, the higher the test temperature and the lower strain-rate, the higher elongation and lower the yield stress (Figure 4a,c,d, Table 1).

The sections of true stress vs. true strain diagrams corresponding to the first stages of high-temperature deformation at strain rate $4.2 \times 10^{-4} \mathrm{~s}^{-1}$ are shown in Figure 4a (inset in the figure). A standard procedure for the determination of trues stress and the true strain was used: $\sigma_{T}=\sigma_{E}\left(1+\varepsilon_{E}\right), \varepsilon_{T}=\ln \left(1+\varepsilon_{E}\right)$, where $\sigma_{T}$ and $\varepsilon_{T}$ are true stress and true strain, respectively, $\sigma_{E}$ and $\varepsilon_{E}$ are engineering stress and engineering strain, respectively. This approach is correct if the specimen deforms uniformly without neck formation [30,31]. In situ observations of the specimens during high-temperature tensile deformation showed that at elongations lower than $300 \%\left(\varepsilon_{T} \sim 1.4\right)$, specimens deformed uniformly. So, taking into account indicated limitation, only initial stages of specimen deformation were analyzed (in an inset in Figure 1a, $\varepsilon_{T}<0.9$ ).

Analysis of true stress vs. true strain diagrams showed that for temperature of $800{ }^{\circ} \mathrm{C}$, corresponding to lower limit of the SP interval, the total elongation to failure was smaller than $400 \%$ (Table 1), and true stress vs. true strain diagram was characterized by pronounced strain hardening stage (inset in Figure 4a). The latter could testify to prevailing recrystallization and intragranular plastic deformation during tension at $800^{\circ} \mathrm{C}$. For deformation in temperature interval $850-950{ }^{\circ} \mathrm{C}$, very limited strain hardening stages were observed (inset in Figure 4a), and superplastic flow was accompanied by weak dependence of flow stress on the strain. At the higher temperature $\left(1000^{\circ} \mathrm{C}\right)$, grain growth processes prevailed under grain boundary sliding mechanism, and this was accompanied by a decrease in elongation to failure and presence of extended strain hardening stage on true stress vs. true strain diagram (Table 1, Figure 4a). 

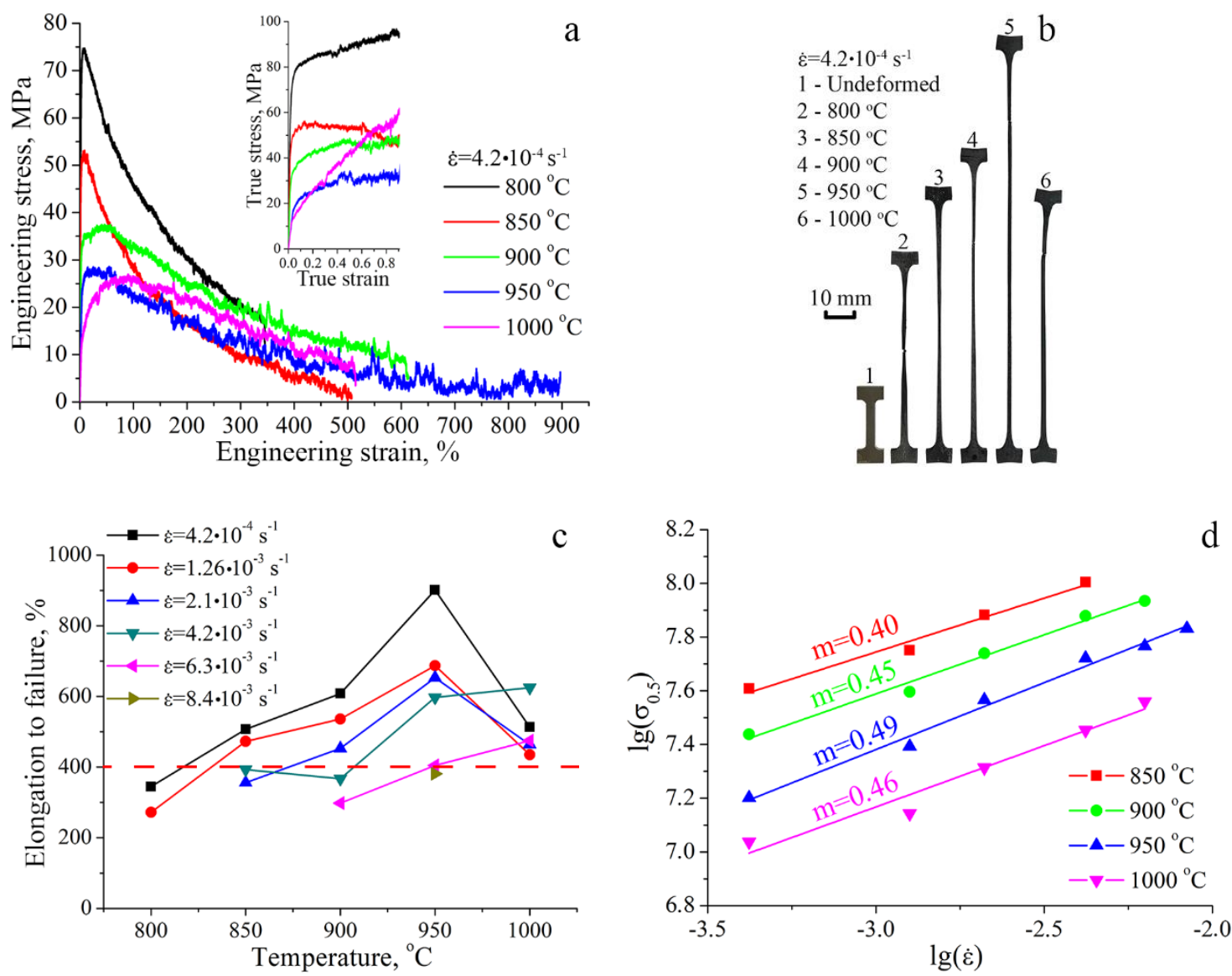

Figure 4. Engineering stress vs. engineering strain diagrams (a) and the photographs of the specimens after high-temperature deformation to failure (b) at strain rate $4.2 \times 10^{-4} \mathrm{~s}^{-1}$. Inset in (a) demonstrates true stress vs. true strain diagrams. Elongation of the specimens processed via thermal-mechanical treatment with dependence on test temperature and strain rate (c) and strain-rate sensitivity coefficient for different test temperatures (d).

Table 1. Values of elongation to failure $(\delta, \%)$ and yield strength $\left(\sigma_{0.2}, \mathrm{MPa}\right)$ at different temperatures $\left({ }^{\circ} \mathrm{C}\right)$ and strain rates $\left(\mathrm{s}^{-1}\right)$ for V-HNS (high-nitrogen steel) after multistep thermal-mechanical treatment.

\begin{tabular}{|c|c|c|c|c|c|c|c|}
\hline $\begin{array}{l}\text { Strain Rate } \\
\text { Temperature }\end{array}$ & $\begin{array}{c}0.42 \times 10^{-3} \\
\delta / \sigma_{0.2}\end{array}$ & $\begin{array}{c}1.26 \times 10^{-3} \\
\delta / \sigma_{0.2}\end{array}$ & $\begin{array}{c}2.1 \times 10^{-3} \\
\delta / \sigma_{0.2}\end{array}$ & $\begin{array}{c}4.2 \times 10^{-3} \\
\delta / \sigma_{0.2}\end{array}$ & $\begin{array}{c}6.3 \times 10^{-3} \\
\delta / \sigma_{0.2}\end{array}$ & $\begin{array}{c}8.4 \times 10^{-3} \\
\delta / \sigma_{0.2}\end{array}$ & m \\
\hline 25 & $1.8 / 1269$ & - & - & - & - & - & - \\
\hline 800 & $345 / 55$ & $272 / 66$ & - & - & - & - & - \\
\hline 850 & $507 / 35$ & $473 / 47$ & $356 / 66$ & $393 / 90$ & - & - & 0.40 \\
\hline 900 & $608 / 25$ & $536 / 37$ & $453 / 48$ & $367 / 68$ & $298 / 71$ & - & 0.45 \\
\hline 950 & $901 / 15$ & $687 / 23$ & $653 / 33$ & $597 / 49$ & $405 / 53$ & $381 / 60$ & 0.49 \\
\hline 1000 & $513 / 11$ & $435 / 13$ & $464 / 18$ & $625 / 24$ & $475 / 31$ & - & 0.46 \\
\hline
\end{tabular}

The relationship between elongation to failure and deformation temperature for different strain rates is plotted in Figure 4c. Supposing 400\% elongation as a critical value, the superplasticity could be realized in Fe-19Cr-22Mn-1.5V-0.3C-0.6N steel in the temperature interval from $850{ }^{\circ} \mathrm{C}$ to $1000{ }^{\circ} \mathrm{C}$. At deformation temperature $950{ }^{\circ} \mathrm{C}$ and initial strain rate $4.2 \times 10^{-4} \mathrm{~s}^{-1}$, the elongation to failure reached $900 \%$.

Strain-rate sensitivity coefficient $\mathrm{m}$ is one of the main characteristics of the superplastic flow. It could be determined using the following relation $[9,16]$ :

$$
\mathrm{m}=\mathrm{d} \ln (\sigma) / \mathrm{d} \ln (\dot{\varepsilon})
$$


here $\sigma$ is flow stress, and $\dot{\varepsilon}$ is the strain-rate value. Typically for superplastic flow, the m-value should be higher than $0.3[9,16]$. In the present investigation, a $\sigma_{0.5}$ value corresponding to $0.5 \%$ of plastic strain was used for calculation of $\mathrm{m}$-value because it corresponded to stable plastic flow of material and was very close to the yield stress. Moreover, for each test temperature, a dynamic recrystallization effect was still minor at $0.5 \%$ of plastic strain, and calculated m-values were constructed for different strain-rates but the same grain size and microstructure of the V-HNS. In the temperature and strain-rates intervals from $850{ }^{\circ} \mathrm{C}$ to $1000^{\circ} \mathrm{C}$ and from $4.2 \times 10^{-4}$ to $8.4 \times 10^{-3} \mathrm{~s}^{-1}$, the $\mathrm{m}$-value possessed high values $0.40-0.49$ (Figure $4 \mathrm{~d}$ ), which are peculiar for superplastic flow [1-3]. The $\mathrm{m}$-value increased to the highest value of 0.49 at the temperature of $950{ }^{\circ} \mathrm{C}$ and then decreased with growth in temperature up to $1000{ }^{\circ} \mathrm{C}$ (Figure $4 \mathrm{~d}$ ). This correlated with a change in elongation with test temperature (Table 1). The increase in strain rate in the range $4.2 \times 10^{-4}-2.1 \times 10^{-3} \mathrm{~s}^{-1}$ did not vary the peak temperature corresponding to maximum elongation. The further increase in strain rate moved it to higher temperatures, but in the given test temperature interval, the peak temperature could not be determined definitely for the strain rates higher than $2.1 \times 10^{-3} \mathrm{~s}^{-1}$ (Figure $4 \mathrm{c}$ ).

Fractured specimens were homogeneously deformed (Figure $4 \mathrm{~b}$ ). The realization of superplastic behavior in V-HNS during high-temperature tests was accompanied by a formation of characteristic relief on the surfaces of the specimens tensile tested in a vacuum and having polished smooth surfaces before the test. SEM images of the lateral surfaces of the specimens at different values of elongation after the tensile test at $950{ }^{\circ} \mathrm{C}$ and the strain rate of $4.2 \times 10^{-4} \mathrm{~s}^{-1}$ are shown in Figure 5 . At the early stages of high-temperature deformation ( $40 \%$ and $100 \%$ elongation), equiaxial fine grains were clearly visible on SEM images (Figure 5a,b). This relief indicated the grain-boundary sliding mechanism (marked by arrows), which is peculiar for superplastic flow [1,2]. No traces of intragranular slip were observed on the lateral surfaces of the specimens at these elongation values. For the temperature $950{ }^{\circ} \mathrm{C}$, the mean grain size determined from the SEM image in Figure 5a was $0.74 \pm 0.15 \mu \mathrm{m}$. This testified to the recrystallization and transformation of the deformation-assisted microstructure produced by multistep thermal-mechanical treatment (Figure 2a) into fine-grained microstructure during high-temperature deformation (Figure 5a). The absence of descending stage in true stress vs. true strain diagrams in the early stages of the plastic flow (Figure 4a, inset) evidenced that recrystallization occurred during pre-deformation heat of the specimens up to the test temperature, and the beginning of the plastic flow was associated basically with the grain-boundary sliding mechanism of deformation. The deformation was accompanied by the formation of a specific relief (surface level irregularities) on the surface of the specimens (in Figure 5a,b) that confirmed the prevailing of the grain-boundary sliding deformation mechanism. At higher elongation (400 and 900\%), cavities and traces of intragranular slip (shown by yellow contours) could be seen on SEM images (Figure $5 c, d$ ).
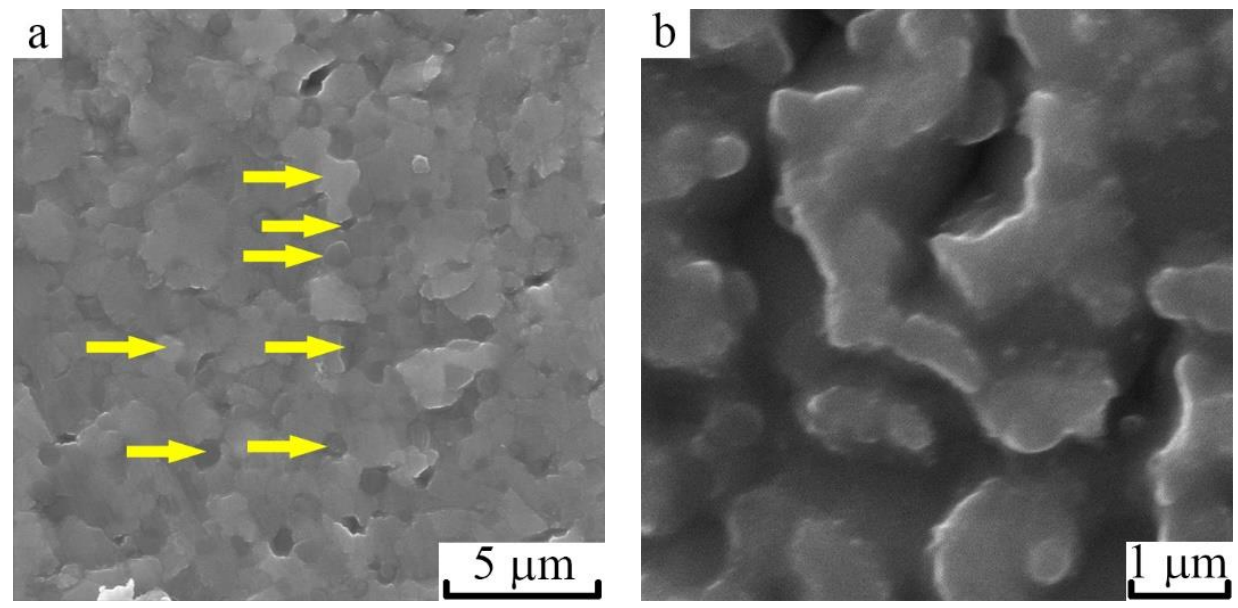

Figure 5. Cont. 

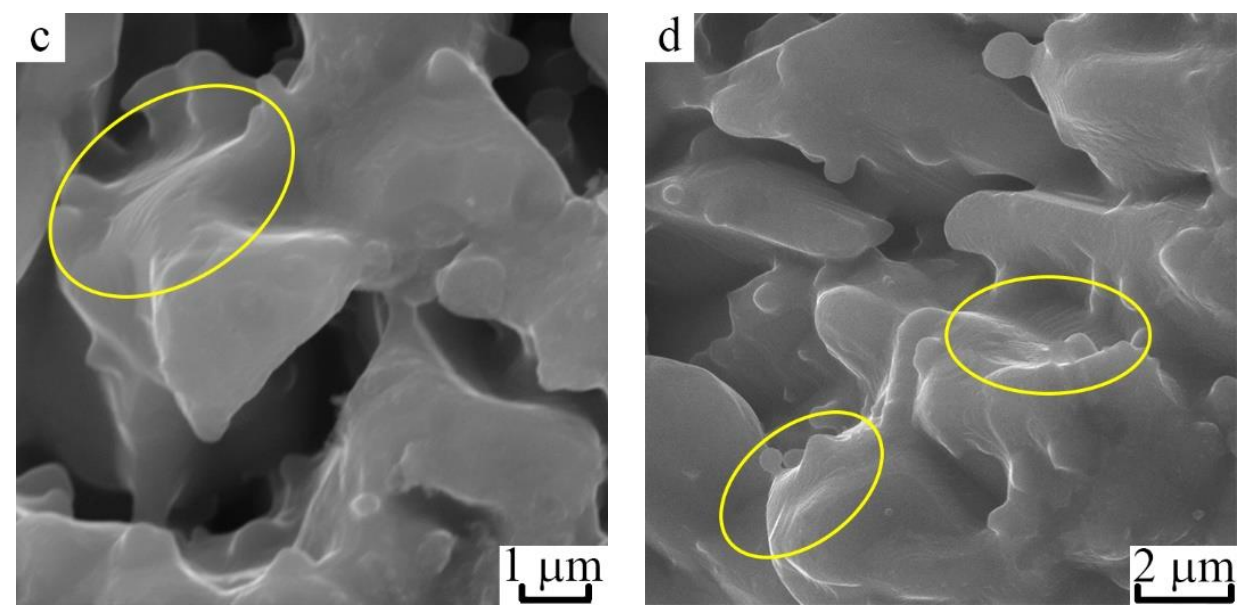

Figure 5. SEM images of the lateral surfaces of the specimens after tensile test at temperature $950{ }^{\circ} \mathrm{C}$, strain rate $4.2 \times 10^{-4} \mathrm{~s}^{-1}$ and corresponded to different elongation values: (a) $40 \%$; (b) $100 \%$; (c) $400 \%$; (d) $900 \%$. Yellow arrows in (a) show examples of grain boundary sliding mechanism, and yellow contours in (c) and (d) show examples of intragranular slip traces.

The EBSD phase and structural maps for the working part of tensile specimens after high-temperature deformation to failure at $950{ }^{\circ} \mathrm{C}$ and strain rate of $4.2 \times 10^{-4} \mathrm{~s}^{-1}$ are shown in Figure 6. Both round-shaped and slightly elongated grains are seen in Figure 6a. The elongated form of the grains could be associated with a portion of intragranular slip during high-temperature deformation. The average size of austenitic grains in Figure $6 \mathrm{a}-\mathrm{d}$ was $1.5 \pm 1.0 \mu \mathrm{m}$. The boundaries in Figure $6 \mathrm{c}$ possessed mainly high-angle misorientations, and inverse pole figure (inset in Figure $6 \mathrm{~b}$ ) testified the random orientation of austenitic grains after superplastic deformation at $950{ }^{\circ} \mathrm{C}$. Kernel's average misorientations inside of grains did not exceed $2^{\circ}$ (Figure $6 \mathrm{~d}$ ). These features gave evidence for grain boundary sliding as a dominating deformation mechanism during high-temperature tensile deformation of the specimens.
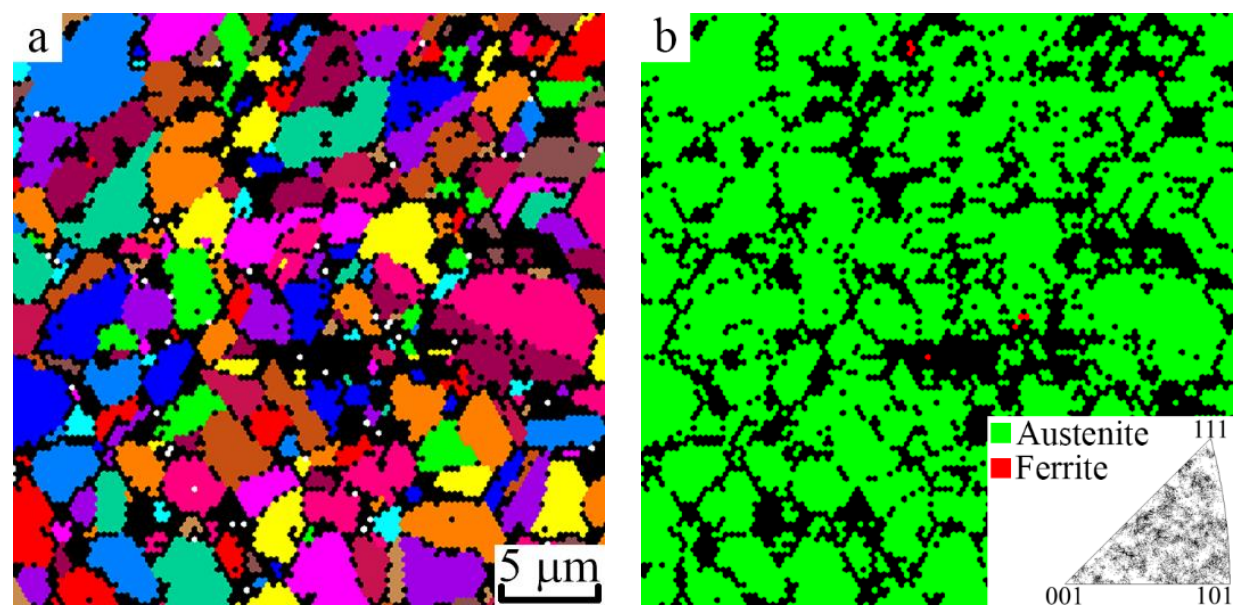

Figure 6. Cont. 

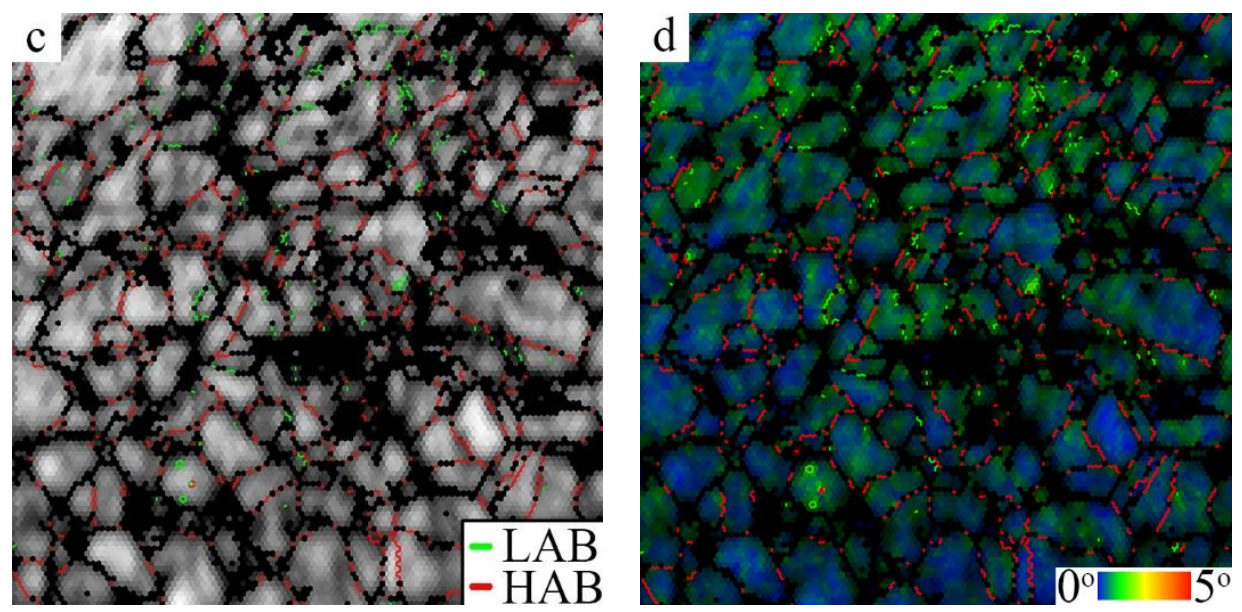

Figure 6. EBSD color-coded maps corresponded to the working part of the specimen after tensile test to $900 \%$ elongation at $950{ }^{\circ} \mathrm{C}$ and the strain rate of $4.2 \times 10^{-4} \mathrm{~s}^{-1}$ : grain map (a), phase map and [001] inverse pole figure for austenitic phase (b), grain boundary map combined with image quality map (c), and Kernel average misorientation map combined with boundary map (d). All maps were constructed for the austenitic phase (normal direction) with $\mathrm{CI}>0.3$ and step size $0.3 \mu \mathrm{m}$. LAB-low-angle boundaries, HAB-high-angle boundaries. The EBSD maps for transverse and rolling directions were similar to maps in $(\mathbf{a}-\mathbf{d})$.

Phase map in Figure $6 \mathrm{~b}$ testified to the fact that after high-temperature deformation to $900 \%$ elongation, the V-HNS still possessed austenitic structure. The ferrite fraction after deformation at $950{ }^{\circ} \mathrm{C}$ was less than $5 \%$ (Figure $6 \mathrm{~b}$ ). Consequently, the high-temperature deformation behavior in Fe-19Cr-22Mn-1.5V-0.3C-0.6N steel was not associated with the formation of $(\alpha+\gamma)$ micro duplex structure, which was more familiar to superplastic flow in steels $[5,18]$.

Therefore, multistep thermal-mechanical treatment provided the formation of a composite microstructure characterized by a severely deformed misoriented austenitic structure with a high volume fraction of precipitates. This structure was a characteristic of severely deformed austenitic steels with high interstitial content $[32,33]$. During heating of the specimens to the test temperature, this structure recrystallized into fine-grained austenitic one, which was stabilized by numerous precipitates. The high-temperature deformation of such fine-grained austenitic structure was associated with a grain boundary sliding mechanism. A limited grain growth occurred during superplastic deformation of Fe-19Cr-22Mn-1.5V-0.3C-0.6N steel. Grain coarsening could be suppressed by the carbonitride phase produced by initial thermal-mechanical processing (rolling with intermediate anneals) and, additionally, precipitate nucleation and growth during high-temperature deformation.

Precipitate-free single-phase austenitic steels (or with a low fraction of precipitates) demonstrated low superplastic-assisted elongation in the interval from $180 \%$ to a maximum 300\% $[1,5,15,28]$. Mineura [29] reported much higher elongation (527\%) at $800{ }^{\circ} \mathrm{C}$ and strain rate $\sim 10^{-4} \mathrm{~s}^{-1}$ for ultra-high nitrogen austenitic steel Fe-20Cr-10Ni-0.7N (mass.\%). They described the superplasticity by precipitation of fine chromium nitrides, which were promoted by two-step cold rolling with intermediate anneal at $1000{ }^{\circ} \mathrm{C}$. These fine nitrides were, probably, unstable against growth being heated above $800{ }^{\circ} \mathrm{C}$, and elongation to failure decreased when test temperature rose above this temperature. In present Fe-19Cr-22Mn-1.5V-0.3C-0.6N V-HNS, the superplastic-assisted elongation grew to the temperature $950^{\circ} \mathrm{C}$, the peak on the $\delta(\mathrm{T})$-dependence was moved to the higher temperatures, and the value of elongation to failure was higher at $\mathrm{T}>850^{\circ} \mathrm{C}$ as compared to Mineura [29] data. This was associated with the higher stability of $\mathrm{V}$-containing precipitates against coarsening, coagulation, or dissolution during high-temperature deformation as compared to Cr-based particles. The pinning effect of $\mathrm{V}(\mathrm{C}, \mathrm{N})$ precipitates on the moving grain boundaries during recrystallization was noted in [34]. The authors showed that with increasing in V-carbonitride fraction, the plateau on the recrystallization 
fraction vs. recrystallization time started in earlier times and at higher testing temperatures [34]. The positive effect of stable disperse particles was also associated with the fact that they could act as recrystallization nuclei and promote grain refinement [1]. The direct comparison of the elongation values of the data for V-free Fe-20Cr-10Ni-0.7N [29] and V-alloyed Fe-19Cr-22Mn-1.5V-0.3C-0.6N (present research) steels at similar deformation regimes (temperature and strain rate) was difficult because the ratios of the gauge length to width were different for them. Namely, it was 1.6 for [29] and 3.3 in the present research. According to data [8], if this ratio increases, the elongation of the specimens could be reduced. Therefore, at deformation temperature $800^{\circ} \mathrm{C}$ and strain rate $\sim 10^{-4} \mathrm{~s}^{-1}$, the difference in elongation of the present steel (345\% at ratio 3.3$)$ and $\mathrm{V}$-free $\mathrm{Fe}-20 \mathrm{Cr}-10 \mathrm{Ni}-0.7 \mathrm{~N}$ steel [29] (527\% at ratio 1.6) could be associated only with the difference in geometry of the specimens.

\section{Conclusions}

A deformation-assisted austenitic microstructure with the high volume fraction of nitrides was designed in V-alloyed Fe-19Cr-22Mn-1.5V-0.3C-0.6N steel, which demonstrated the superplastic behavior with $900 \%$ elongation to failure at deformation temperature $950{ }^{\circ} \mathrm{C}$ and strain rate of $4 \times 10^{-4} \mathrm{~s}^{-1}$. Misoriented grain/subgrain austenitic microstructure with a high density of deformation-assisted defects and precipitates (with a mean size of $214 \mathrm{~nm}$ ) was produced in the steel by multiple cold rolling with intermediate anneals. During high-temperature tests, this structure recrystallized into the fine-grained austenitic structure, which was stabilized by V-containing and $\mathrm{Cr}$-based precipitates. A limited grain growth occurred during superplastic deformation of Fe-19Cr-22Mn-1.5V-0.3C-0.6N steel and was suppressed by the carbonitride phase produced by initial thermal-mechanical processing (rolling with intermediate anneals) and/or precipitate nucleation and growth during high-temperature deformation. In tensile deformation in the strain-rate-temperature deformation regime from 850 to $1000{ }^{\circ} \mathrm{C}$ and from $4 \times 10^{-4} \mathrm{~s}^{-1}$ to $6 \times 1^{-3} \mathrm{~s}^{-1}$, this microstructure manifested the characteristics of superplastic flow: elongation to fracture higher than $400 \%$, high strain-rate sensitivity exponent $\mathrm{m}=0.40-0.49$, grain boundary sliding mechanism.

Author Contributions: Conceptualization, E.A. and N.G.; Investigation, S.A., V.M., M.P., G.M., E.M., and K.R.; Methodology, S.A.; Supervision, E.A.; Writing-original draft, S.A.; Writing-review and editing, E.A. All authors have read and agreed to the published version of the manuscript.

Funding: The research was supported by the Russian Science Foundation (project No. 17-19-01197). The study was conducted using the equipment of the Institute of Strength Physics and Materials Science (NANOTECH center).

Conflicts of Interest: The authors declare no conflict of interest.

\section{References}

1. Padmanabhan, K.A.; Prabu, S.B.; Mulyukov, R.R.; Nazarov, A.; Imayev, R.M.; Chowdhury, S.G. Superplasticity: Common Basis for a Near-Ubiquitous Phenomenon; Springer-Verlag GmbH: Berlin, Germany, 2018.

2. Kaibyshev, O.A. Superplasticity of Alloys, Intermetallides and Ceramics; Springer-Verlag GmbH: Berlin, Germany, 1992.

3. Kawasaki, M.; Langdon, T.G. Superplasticity in Ultrafine-Grained Materials. Rev. Adv. Mater. Sci. 2018, 54, 46-55. [CrossRef]

4. Langdon, T. An evaluation of the strain contributed by grain boundary sliding in superplasticity. Mater. Sci. Eng. A 1994, 174, 225-230. [CrossRef]

5. Maehara, Y.; Langdon, T.G. Superplasticity of steels and ferrous alloys. Mater. Sci. Eng. A 1990, 128, 1-13. [CrossRef]

6. Goldberg, A.; Ruano, O.A.; Sherby, O.D. Development of ultrafine microstructures and superplasticity in Hadfield manganese steels. Mater. Sci. Eng. A 1992, 150, 187-194. [CrossRef]

7. Cao, W.; Huang, C.; Wang, C.; Dong, H.; Weng, Y. Dynamic reverse phase transformation induced high-strain-rate superplasticity in low carbon low alloy steels with commercial potential. Sci. Rep. 2017, 7, 9199. [CrossRef] 
8. Han, J.; Kang, S.-H.; Lee, S.-J.; Kawasaki, M.; Lee, H.-J.; Ponge, D.; Raabe, D.; Lee, Y.-K. Superplasticity in a lean Fe-Mn-Al steel. Nat. Commun. 2017, 8, 751. [CrossRef]

9. Özdemir, N.; Orhan, N. Investigation on the superplasticity behavior of ultrahigh carbon steel. Mater. Des. 2006, 27, 706-709. [CrossRef]

10. Li, S.; Ren, X.; Ji, X.; Gui, Y. Effects of microstructure changes on the superplasticity of 2205 duplex stainless steel. Mater. Design. 2014, 55, 146-151. [CrossRef]

11. Zhang, H.; Zhang, I.; Cheng, X.; Xu, L.; Bai, B. Superplastic behavior during warm deformation of martensite in medium carbon steel. Scr. Mater. 2010, 62, 798-801. [CrossRef]

12. Misra, R.D.K.; Hu, J.; Yashwanth, I.V.S.; Challa, V.S.A.; Du, L.-X.; Sun, G.-S.; Xie, H. Phase reverted transformation-induced nanograined microalloyed steel: Low temperature superplasticity and fracture. Mater. Sci. Eng. A 2016, 668, 105-111. [CrossRef]

13. Zhang, H.; Bai, B.; Raabe, D. Superplastic martensitic Mn-Si-Cr-C steel with $900 \%$ elongation. Acta Mater. 2011, 59, 5787-5802. [CrossRef]

14. Ren, X.; Chen, X.; Xiong, Z. Characterization and analysis of diffusion bonding process in a Cr25Ni7Mo4MnSi duplex stainless steel. J. Manuf. Process. 2018, 34, 603-613. [CrossRef]

15. Yagodzinskyy, Y.; Pimenoff, J.; Tarasenko, O.; Romu, J.; Nenonen, P.; Hänninen, H. Grain Refinement Process for Superplastic Forming of AISI 301 and 304L Austenitic Stainless Steels. Mater. Sci. Technol. 2004, 20, 925-929. [CrossRef]

16. Sun, G.S.; Du, L.X.; Hu, J.; Xie, H.; Misra, R.D.K. Low temperature superplastic-like deformation and fracture behavior of nano/ultrafine-grained metastable austenitic stainless steel. Mater. Des. 2017, 117, $223-231$. [CrossRef]

17. Cao, Z.; Wu, G.; Sun, X.; Wang, C.; Ponge, D.; Cao, W. Revealing the superplastic deformation behaviors of hot rolled 0.10C5Mn2Al steel with an initial martensitic microstructure. Scr. Mater. 2018, 152, 27-30. [CrossRef]

18. Zhang, H.; Ponge, D.; Raabe, D. Superplastic Mn-Si-Cr-C duplex and triplex steels: Interaction of microstructure and void formation. Mater. Sci. Eng. A 2014, 610, 355-369. [CrossRef]

19. Sagradi, M.; Pulino-Sagradi, D.; Medrano, R.E. The effect of the microstructure on the superplasticity of a duplex stainless steel. Acta Mater. 1998, 46, 3857-3862. [CrossRef]

20. Song, J.L.; Blackwell, P.L. Superplastic behavior of commercial duplex stainless steel SAF 2304. Mater. Sci. Technol. 1999, 15, 1285-1292. [CrossRef]

21. Osada, K.; Uekoh, S.; Ebato, K. Superplasticity of As-rolled Duplex Stainless Steel. Trans. Iron Steel Inst. Jpn. 1987, 27, 713-718. [CrossRef]

22. Gavriljuk, V.G.; Berns, H. High Nitrogen Steels; Springer: Berlin, Germany, 1999.

23. Reed, R. Nitrogen in austenitic stainless steels. JOM 1989, 41, 16-21. [CrossRef]

24. Bannykh, O.A.; Blinov, V.M. On the effect of discontinuous decomposition on the structure and properties of high-nitrogen steels and on methods for suppression thereof. Steel Res. 1991, 62, 38-45. [CrossRef]

25. Blinov, V.M. Progress in the study of high-nitrogen corrosion-resistant aging nonmagnetic vanadium steels. Russ. Metall. (Met.) 2007, 2, 127-135. [CrossRef]

26. Astafurova, E.; Moskvina, V.; Maier, G.; Melnikov, E.; Galchenko, N.; Astafurov, S.; Gordienko, A.; Burlachenko, A.; Smirnov, A.; Bataev, V.; et al. The effect of test temperature on deformation microstructure and fracture mechanisms in CrMn high-nitrogen steels alloyed (0-3 wt.\%) with vanadium. Mater. Sci. Forum 2018, 941, 27-32. [CrossRef]

27. Astafurova, E.G.; Moskvina, V.A.; Maier, G.G.; Gordienko, A.I.; Burlachenko, A.G.; Smirnov, A.I.; Bataev, V.A.; Galchenko, N.K.; Astafurov, S.V. Low-temperature tensile ductility by V-alloying of high-nitrogen CrMn and CrNiMn steels: Characterization of deformation microstructure and fracture micromechanisms. Mater. Sci. Eng. A 2019, 745, 265-278. [CrossRef]

28. Astafurova, E.G.; Astafurov, S.V.; Ratochka, I.V.; Mishin, I.P.; Lykova, O.N.; Maier, G.G.; Melnikov, E.V.; Moskvina, V.A. The Influence of Warm abc-Pressing on the Structure and Mechanical Properties of Stable Chromium-Nickel-Molybdenum Steel. Russ. Phys. J. 2018, 61, 1062-1069. [CrossRef]

29. Mineura, K.; Tanaka, K. Superplasticity of $20 \mathrm{Cr}-10 \mathrm{Ni}-0.7 \mathrm{~N}$ (wt $\%$ ) ultra-high nitrogen austenitic stainless steel. J. Mater. Sci. 1989, 24, 2967-2970. [CrossRef]

30. Hyun, H.C.; Kim, M.; Bang, S.; Lee, H. On acquiring true stress-strain curves for sheet specimens using tensile test and FE analysis based on a local necking criterion. J. Mater. Res. 2014, 29, 695-707. [CrossRef] 
31. Tu, S.; Ren, X.; He, J.; Zhang, Z. Stress-strain curves of metallic materials and post-necking strain hardening characterization: A review. Fat. Fract. Eng. Mater. Struct. 2019, 1-17. [CrossRef]

32. Maier, G.G.; Astafurova, E.G.; Moskvina, V.A.; Melnikov, E.V.; Astafurov, S.V.; Fortuna, A.S.; Galchenko, N.K.; Smirnov, A.S.; Bataev, V.A. Influence of hydrogen-charging on microstructure and microhardness of high-nitrogen austenitic steel processed by high-pressure torsion. AIP Conf. Proc. 2018, 2051, 020182.

33. Astafurova, E.G.; Tukeeva, M.S.; Maier, G.G.; Melnikov, E.V.; Maier, H.J. Microstructure and mechanical response of single-crystalline high-manganese austenitic steels under high-pressure torsion: The effect of stacking-fault energy. Mater. Sci. Eng. A 2014, 604, 166-175. [CrossRef]

34. Buken, H.; Kozeschnik, E. A model for static recrystallization with simultaneous precipitation and solute drag. Metallurg. Mater. Trans. A 2017, 48, 2812-2818. [CrossRef]

(C) 2019 by the authors. Licensee MDPI, Basel, Switzerland. This article is an open access article distributed under the terms and conditions of the Creative Commons Attribution (CC BY) license (http://creativecommons.org/licenses/by/4.0/). 